\title{
GLOSA SOBRE NATUREZA E HISTÓRIA
}

Cristiane Souza Borzuk ${ }^{I}$

Resumo: O objetivo deste trabalho é tecer algumas considerações sobre natureza e história. Partindo do pressuposto de que, em nossos dias, há uma tendência a atribuir a causas individuais, geralmente associadas a uma 'natureza humana invariável' ou a alterações físico-químicas, a origem de comportamentos considerados hostis ou incompatíveis com o estágio de desenvolvimento da sociedade atual, estas notas se propõem a discutir os conceitos de natureza e história e seu lugar na constituição individual. Trataremos a questão partindo de dois pontos. $\mathrm{O}$ primeiro, $\mathrm{o}$ desenvolvimento do indivíduo ao longo da civilização ocidental. O segundo, a partir do processo de socialização nas sociedades administradas. O referencial teórico e metodológico é a Teoria Crítica da Sociedade.

Palavras-chave: Natureza. História. Indivíduo. Teoria Crítica da Sociedade.

\section{GLOSS ABOUT NATURE AND HISTORY}

Abstract: This article aims to make some considerations about nature and history. Assuming that, currently, there is a tendency to attribute to individual causes, usually associated with an 'invariable human nature' or physicochemical alterations, the origin of behaviors considered hostile or incompatible with the stage of development of today's society, these annotations propose to discuss the concepts of nature and history and their place in the individual constitution. We will address the issue from two points: First, the development of the individual throughout Western civilization, and the second one, based on the socialization process in administered societies. The theoretical and methodological framework is the Critical Theory of Society.

Keywords: Nature. History. Individual. Critical Theory of Society.

Artigo recebido em 31/10/2020 e aprovado em 07/08/2021. 


\section{GLOSA SOBRE NATUREZA E HISTÓRIA \\ CRISTIANE SOUZA BORZUK}

O objetivo deste texto é tecer algumas considerações sobre natureza e história. Partindo do pressuposto de que, em nossos dias, há uma tendência a atribuir a causas individuais, geralmente associadas a uma 'natureza humana invariável' ou a alterações físico-químicas, a origem de comportamentos considerados hostis ou incompatíveis com o estágio de desenvolvimento da sociedade atual, como o crime e a loucura, estas notas se propõem a se debruçar sobre as noções de natureza e história no que dizem respeito à constituição individual.

Estas concepções, que se estendem desde noções advindas do senso comum, como a ideia de que 'pau que nasce torto, morre torto', até aquelas que se localizam no que é considerado o que há de mais avançado no campo científico, como concepções derivadas do campo das ciências biológicas, tendem a ignorar o papel dos fatores históricos e econômicos na constituição das individualidades, em evidente processo de naturalização dos processos que não podem ser descolados dos determinantes históricos e econômicos.

Partimos da hipótese de que a atribuição a fatores naturais como causas de comportamentos não é apenas um fato isolado, referente a este ou aquele comportamento, mas configura-se como uma tendência que vem se consolidando a cada dia nas sociedades ocidentais. Neste artigo, esta questão será tratada considerando dois pontos. O primeiro, o desenvolvimento do indivíduo ao longo da civilização ocidental; o segundo, a partir do processo de socialização nas sociedades administradas.

\section{De Leibniz a Comte}

A concepção que defende a ideia de que os indivíduos são o que são em virtude de uma natureza humana invariável tem seus fundamentos na metafísica de Leibniz. Nos primórdios da sociedade liberal, Leibniz desenvolve a tese segundo a qual o universo é composto por 'unidades de força'. Tal tese deriva de sua concepção de mundo que, oposta ao mecanicismo cartesiano, propõe a noção de que os seres não são como máquinas em movimento, mas como forças vivas ${ }^{\mathrm{II}}$. Segundo Leibniz, estas unidades de força, as mônadas, que são todos os seres vivos, inclusive os homens, viriam ao mundo por desígnio divino: “Assim, só Deus é unidade primitiva, ou a substância simples originária de que todas as Mônadas criadas ou derivadas são produções e nascem de momento a momento, digamos assim, por Fulgurações contínuas da Divindade"

Leibniz enumera uma série de sentenças que caracterizam as mônadas. Para ele a mônada:

(...) é apenas uma substância simples que entra nos compostos. Simples, quer dizer: sem partes... Ora, onde não há partes, não há extensão, nem figura, nem divisibilidade possíveis, e, assim, as Mônadas são os verdadeiros Átomos da Natureza, e, em uma palavra, os Elementos das coisas ${ }^{\text {IV }}$

E, mais adiante, complementa:

\footnotetext{
Não há meio também de explicar como a Mônada possa ser alterada ou modificada em seu íntimo por outra criatura qualquer, pois nada se lhe pode transpor, nem se pode conceber nela algum movimento interno que, de fora, seja excitado, dirigido, aumentado ou diminuído lá dentro, como nos compostos, onde há mudança entre as partes. As Mônadas não têm janelas por onde qualquer coisa possa entrar ou $\operatorname{sair}^{\mathrm{V}}$.
} 


\section{GLOSA SOBRE NATUREZA E HISTÓRIA \\ CRISTIANE SOUZA BORZUK}

Destes elementos pode-se compreender a concepção de indivíduo e de sociedade derivada do pensamento de Leibniz: o indivíduo seria o elemento mais simples, indivisível, que, unido aos outros, formaria a sociedade, uma somatória de individualidades; dito de outra maneira, "o composto é apenas a reunião ou aggregatum dos simples"VI. Esta concepção é prenhe de consequências. Segundo Horkheimer e Adorno $^{\mathrm{VII}}$, subjacente a ela encontra-se o modelo conceitual para a visão individualista da emergente sociedade burguesa. A mônada, portadora de alguma autonomia, é capaz de vender sua força de trabalho e competir em um mundo em que o capitalismo se impunha enquanto modo de produção. Ao mesmo tempo, será o indivíduo responsável pelo mal, já que não pode ser influenciada pelo todo. Assim, é possível justificar teoricamente os problemas decorrentes dos conflitos de interesses entre as classes sociais, e das mazelas oriundas do acelerado processo de industrialização.

Um paradoxo se coloca aqui. Em seu "Discurso de Metafísica"VIII, Leibniz afirma que Deus “(...) possuindo suprema e infinita sabedoria, age de forma mais perfeita não só em sentido metafísico, mas também moralmente”. Ora, se Deus, de acordo com a metafísica de Leibniz, cria o "melhor dos mundos possível" para se viver, e "em harmonia com o plano criador", sendo as mônadas perfeitas, inclusive moralmente, como se explicam os 'desvios'? Como se explica a existência do 'mal'? Leibniz certamente não atribui a Deus a responsabilidade por tal existência: “(...) as criaturas devem suas perfeições à influência divina, e as imperfeições à sua própria natureza" ${ }^{\text {,IX }}$. Em outro texto ele confirma a sua posição:

Entretanto, vê-se claramente não ser Deus a causa do mal, pois não só o pecado original se apoderou da alma depois da perda da inocência dos homens, mas ainda anteriormente havia uma limitação ou imperfeição conatural a todas as criaturas, tornando-as pecáveis ou suscetíveis de pecar ${ }^{\mathrm{X}}$

Deste modo, mesmo que cada ser venha ao mundo dotado de perfeição, também possui limitações originais. Ainda que Deus proveja a todos os seres com as mesmas graças, cada um somente poderá se beneficiar delas de acordo com essa limitação. Deste modo, o crime ou qualquer outra situação que interfira na harmonia do universo criado por Deus, só se justifica com base no mal metafísico, do qual se origina o mal moral, ou seja, na imperfeição original da criatura.

Recusando a ideia de que o indivíduo é meramente aquilo que lhe coube como desígnio da natureza, Comte enfatiza o papel das contingências ambientais na constituição do indivíduo.

Apesar de ser duramente criticado em vários sentidos pelos autores frankfurteanos, Horkheimer e Adorno reconheceram o papel que a concepção de indivíduo elaborada por Comte exerceu na recusa às concepções naturalistas, tal como a formulada por Leibniz. Comte, fazendo referência aos fenômenos considerados por ele relativos à física orgânica (dividida em fisiologia e física social), afirma que "(...) seria impossível tratar o estudo coletivo da espécie como pura dedução do estudo do indivíduo, porquanto as condições sociais, que modificam a ação das leis fisiológicas, constituem precisamente a consideração mais essencial"XI. Segundo esta concepção, os homens, assim como os demais seres vivos, nasceriam como uma entidade biológica individual, dotados de características próprias da espécie, sendo posteriormente modificadas pelas condições sociais. Ainda que Comte considere como fundamentais as condições sociais, elas são secundárias, sendo a sua 'física social' derivada da fisiologia: "Em todos os fenômenos sociais observa-se, primeiramente, a influência das 


\title{
GLOSA SOBRE NATUREZA E HISTÓRIA \\ CRISTIANE SOUZA BORZUK
}

leis fisiológicas do indivíduo e, ademais, alguma coisa de particular que modifica seus efeitos e que provém da ação dos indivíduos uns sobre os outros"XII.

Mesmo que haja o reconhecimento do caráter progressista desta concepção, já que recusa a ideia de uma natureza humana invariável, também se deve indicar seus limites. De um lado podemos dizer, com Horkheimer e Adorno, que "o conceito de individuação biológica é tão abstrato e indeterminado que não pode expressar, de maneira completa e apropriada, o que os indivíduos efetivamente são"XIII. De outro, o simples fato de que natureza e história são concebidas como dois polos distintos, já demonstra a insuficiência desta concepção para apreender o indivíduo e o que ele é em uma sociedade concreta. Segundo Adorno, "La separación de la estática natural de la dinámica histórica conduce a absolutizaciones falsas, separar en algún sentido la dinámica histórica de lo natural asentado insuperablemente (unaufhebbar) en ella conduce a un espiritualismo del malo"XIV .

\section{Natureza e história}

Adorno, em "A ideia de história natural" $X V$, desenvolve o texto com o intuito de suprimir a antítese entre natureza e história:

\begin{abstract}
Si es que la cuestión de la relación entre naturaleza e historia se ha de plantear con seriedad, entonces sólo ofrecerá un aspecto responsable cuando consiga captar al Ser histórico como Ser natural en su determinación histórica extrema, en donde es máximamente histórico, o cuando consiga captar la naturaleza como ser histórico donde en apariencia persiste en sí misma hasta lo más hondo como naturaleza. Ya no se trata de concebir toto coelo el hecho de la historia en general, sometido a la categoría de historicidad, como un hecho natural, sino de retransformar, en sentido inverso, la disponibilidad (Gefügtheit) de los acontecimientos intrahistóricos en disposición (Gefügtsein) de acontecimientos naturales ${ }^{\mathrm{XVI}}$
\end{abstract}

Para ele, não se trata, pois, de procurar um ser puro que seja anterior ao ser histórico, mas compreender que no limite da natureza encontramos a história, e que no limite da história encontramos a natureza. Podemos mesmo dizer que o homem somente realiza a sua natureza separando-se da natureza, sendo histórico.

Isto posto, compreendemos que o indivíduo se constitui na tensão entre natureza e cultura. E nos referimos não apenas a uma natureza individual, particular, nem tampouco somente na cultura entendida como 'meio ambiente' em que o indivíduo particular se desenvolveria, como são postas estas questões atualmente. Isto pelo simples fato de que tanto no indivíduo particular quanto na cultura, encontram-se as marcas de suas origens mais remotas. A própria afirmação comum de que a filogênese se repete na ontogênese nos dá mostras disso. Segundo Horkheimer e Adorno,

\footnotetext{
A humanidade teve que se submeter a terríveis provações até que se formasse o eu, o caráter idêntico, determinado e viril do homem, e toda infância ainda é de certa forma a repetição disso. O esforço para manter a coesão do ego marca-o em todas as suas fases, e a tentação de perdê-lo jamais deixou de acompanhar a determinação cega de conservá-lo ${ }^{\mathrm{XVII}}$.
}

Assim compreendemos que o que deu origem ao que hoje chamamos de indivíduo, não foi perdido, se mantém ainda não apenas como uma herança arcaica. $\mathrm{O}$ passado não se conserva apenas como passado, mas também como presente. 


\section{GLOSA SOBRE NATUREZA E HISTÓRIA \\ CRISTIANE SOUZA BORZUK}

Segundo Horkheimer e Adorno, os mitos, a ciência e o próprio indivíduo, dotado de uma interioridade e de alguma consciência de si, têm uma origem comum: o enfrentamento da natureza. Da impotência diante da força da natureza e do medo frente a ela, surgiu a necessidade de seu entendimento. Se nos mitos já havia a tentativa não apenas de entendimento, mas de controle da natureza para afugentar o perigo, será apenas com o desenvolvimento do conceito, possível em virtude da separação entre sujeito e objeto, que uma nova forma de vida emerge: "É a substituição da herança mágica, isto é, das antigas representações difusas, pela unidade conceptual que exprime a nova forma de vida, organizada com base no comando e determinada pelos homens livres"XVIII.

O conceito, o pensamento, por surgir das relações entre sujeito e objeto, reproduz estas mesmas relações. Assim, a dominação do sujeito sobre a natureza é encarnada no conceito também sob a forma de dominação. Essa nova forma de vida encontra seu mais perfeito significado na lógica formal. A lógica formal, que não se restringe aos procedimentos adotados pela ciência oficial, representa, sobretudo, a forma com que nos relacionamos com o mundo. Levado às últimas consequências, “(...) a multiplicidade das figuras se reduz à posição e à ordem, a história ao fato, as coisas à matéria"XIX . Em outras palavras, o pensamento é reduzido ao cálculo, à fórmula, e os homens a números. Trata-se do domínio, do poder dos homens sobre a natureza desencantada. O que visa o esclarecimento é a soberania do homem sobre toda a existência.

Mas esta pretensão de afastar-se inteiramente da natureza, controlando-a pela razão, tem suas consequências: "Toda tentativa de romper as imposições da natureza rompendo a natureza, resulta numa submissão ainda mais profunda às imposições da natureza"XX.

O eu que emerge deste contexto deve pagar seu tributo: "O despertar do sujeito tem por preço o reconhecimento do poder como o princípio de todas as relações"XXI. E mais: "O eu, que aprendeu a ordem e a subordinação com a sujeição do mundo, não demorou a identificar a verdade em geral com o pensamento ordenador, e essa verdade não pode subsistir sem as rígidas diferenciações daquele pensamento ordenador". XXII Horkheimer e Adorno demonstraram, por meio da análise de um dos textos fundamentais da civilização ocidental, a Odisseia, de Homero, que na antiguidade clássica, muitos elementos essenciais ao mundo burguês já estavam presentes. Para os autores, “(...) as linhas da razão, da liberalidade, da civilidade burguesa se estendem incomparavelmente mais longe do que supõem os historiadores que datam o conceito do burguês a partir tão-somente do fím do feudalismo medieval".XXIII

Por meio do estudo da personagem Ulisses, revelaram o surgimento de um espaço oculto aos seus adversários, no qual se preparavam as estratégias para derrotálos. A força bruta deu lugar à sagacidade e à capacidade de enganar, na busca pelo poder. Mas a condição para a existência dessa capacidade de enganar e dominar o outro pela tática, era a dominação sobre si mesmo. Foi pela renúncia aos desejos, pelo controle sobre as urgências de uma natureza interna, que um eu pôde se formar em Ulisses. Segundo Crochik ${ }^{\text {XIV }}$, "Ulisses, para ser senhor de si mesmo, ou seja, ter uma identidade, teve que se sacrificar, renunciar aos desejos suscitados pela natureza mitologizada, de tal forma que a identidade se construiu em função da negação de parte do Eu".

Segundo Horkheimer e Adorno ${ }^{\mathrm{XXV}}$, o surgimento do eu ocorreu ao mesmo tempo em que o desenvolvimento da razão, no enfrentamento da natureza, derivando da escrita de Homero um modelo, um protótipo da constituição dos indivíduos particulares. Aqui, será também derivada da dominação sobre os desejos que o eu se forma. No 


\section{GLOSA SOBRE NATUREZA E HISTÓRIA \\ CRISTIANE SOUZA BORZUK}

entanto, se consideramos que a formação do eu se dá em virtude do controle sobre uma natureza interna, a exigência e o sentido desse controle são fornecidos pela cultura. Para os autores, "O indivíduo surge, de certo modo, quando estabelece o seu eu e eleva o seu ser-para-si, a sua unicidade, à categoria de verdadeira determinação" XXVI . No entanto, "mesmo essa autoconsciência da singularidade do eu, que não basta para fazer, por si só, um indivíduo, é uma autoconsciência social ${ }^{\mathrm{XXVII}}$.

Assim, consideramos que mesmo as disposições que porventura trazemos ao mundo ao nascer, somente são desenvolvidas em virtude das possibilidades que se apresentam pela cultura. Mais que isso, são significadas socialmente. Ainda que consideremos a existência dessas disposições, longe estamos de estabelecer qualquer relação entre qualquer comportamento ou característica individual, a prática de crimes, ou qualquer ação do indivíduo, com elas. A redução do indivíduo à mera natureza ou, $o$ seu oposto, a uma representação particular do todo, não conseguem captar efetivamente o indivíduo e suas determinações. Horkheimer e Adorno são categóricos. É necessária a “(...) análise das relações sociais concretas e da configuração concreta que o indivíduo assume nessas relações"XXVIII.

\section{Sobre socialização}

Esta afirmação nos remete ao conceito de sociedade e à forma como o indivíduo tem podido existir em virtude das leis que têm regido o contexto em que vivemos. Segundo Horkheimer e Adorno, por sociedade entende-se:

\footnotetext{
Uma espécie de contextura formada entre todos os homens e na qual uns dependem dos outros, sem exceção; na qual o todo só pode subsistir em virtude da unidade das funções assumidas pelos co-participantes, a cada um dos quais se atribui, em princípio, uma tarefa funcional; e onde todos os indivíduos, por seu turno, estão condicionados, em grande parte, pela sua participação no contexto geral ${ }^{\mathrm{XXIX}}$
}

Desta concepção, compreendemos que a sociedade não pode ser considerada somente a partir da descrição dos elementos que a compõem, pois, como dito antes, recusamos a ideia de que o todo se compõe de partes isoladas. Trata-se, sobretudo, de conhecer as relações existentes entre os homens e as leis que as determinam, que se configuram como um 'nexo funcional' sob o qual todos encontram-se submetidos. Mas, dirá Adorno, se efetivamente há entre os homens um nexo funcional que garante a existência em sociedade, e, por conseguinte, a socialização, este nexo não se dá livremente, mas é determinado pela troca:

\footnotetext{
Como as pessoas existem para as outras e são determinadas essencialmente como trabalhadores, deixam de ser mera existência, mero em-si ou estado factual, mas determinam-se a si próprias mediante o que fazem e mediante a relação que reina entre elas, ou seja, a relação de troca ${ }^{X X}$.
}

Nesse sentido, em oposição tanto às teorias que concebem o indivíduo como fruto de sua natureza, quanto como resultado das contingências ambientais, consideramos que o indivíduo desenvolve-se na tensão entre natureza e cultura, em virtude do processo de socialização.

Portanto, não há indivíduos no sentido social do termo, ou seja, homens aptos à possibilidade de existir e existentes como pessoas, dotados de exigências próprias e, sobretudo, atuantes no trabalho, a não ser com referência à sociedade em que vivem e que forma os indivíduos em seu âmago. Por outro 


\section{GLOSA SOBRE NATUREZA E HISTÓRIA \\ CRISTIANE SOUZA BORZUK}

lado, também não há sociedade sem que seu próprio conceito seja mediado pelos indivíduos, pois o processo pelo qual ela se preserva é, afinal, o processo de vida, o processo de trabalho, o processo de produção e reprodução que se conserva mediante os indivíduos isolados, socializados na sociedade. $^{\text {XXXI }}$

Esta afirmação de Adorno é prenhe de consequências. Se efetivamente não é possível chegar a uma fórmula, nos moldes da ciência formal, que explique por que razão se fez isso ou aquilo, é possível conhecer os nexos sociais que subjazem à existência humana e possibilitam níveis individuais distintos de diferenciação e apropriação da cultura.

Segundo Adorno, Herbert Spencer definiu a dinâmica da sociedade a partir do processo de integração progressiva dos vários setores da sociedade. Isso significa que "(...) setores cada vez mais amplos da sociedade se conectam de um modo que os coloca em dependência recíproca"XXXII. De acordo com a teoria de Spencer, quanto maior a integração, maior também seria a diferenciação da sociedade, em virtude das funções distintas surgidas com a divisão do trabalho. Decorrente disso, a diferenciação dos indivíduos também aumentaria. Segundo Horkheimer e Adorno, “(...) a tese da integração progressiva foi confirmada". XXXIII Praticamente nada existe fora do contexto funcional da sociedade. Mesmo o que não participa diretamente do processo produtivo, ou que aparentemente se mantém à margem da sociedade, hoje é capturado.

Por outro lado, a progressiva diferenciação postulada por Spencer, que efetivamente ocorreu em certos momentos do capitalismo concorrencial, não se manteve no capitalismo dos monopólios. Com o aumento da divisão do trabalho, há uma tendência à redução dos momentos específicos do processo social da produção. Segundo Horkheimer e Adorno, “(...) quanto menores são as unidades em que se subdivide o processo social da produção, com o avanço da divisão do trabalho e da racionalização da produção, tanto mais as operações laborais assim subdivididas tendem a assemelhar-se e a perder o seu momento qualitativo específico".XXXIV Os autores exemplificam esta afirmação referindo-se ao trabalho do artesão como incomparavelmente mais diferenciado que o trabalho do operário na indústria.

Essa integração tem ocorrido em proporções gigantescas, e, consequentemente parece estar havendo uma igualmente gigantesca suspensão da diferenciação. E isso não ocorre sem consequências para a vida humana. À redução da diferenciação no mundo do trabalho, corresponde a redução da diferenciação dos próprios indivíduos. No entanto, este controle que atualmente é exercido fundamentalmente pela indústria cultural, não ocorre de modo linear. Segundo Adorno,

(...) nossa sociedade, ao mesmo tempo que se integra cada vez mais, gera tendências de desagregação... A pressão do geral dominante sobre tudo que é particular, os homens individualmente e as instituições singulares, tem uma tendência a destroçar o particular e individual juntamente com seu potencial de resistência. Junto com sua identidade e seu potencial de resistência, as pessoas também perdem suas qualidades, graças a qual têm a capacidade de se contrapor ao que em qualquer tempo novamente seduz ao crime. ${ }^{\text {XXV }}$

\section{Livre arbítrio e determinismo}

Para Kant, na natureza todas as coisas são regidas por leis, entretanto, somente o homem, por ser racional, tem a capacidade de agir de acordo com a 'representação' das leis, ou seja, de acordo com princípios, o que indica que somente o homem possui uma 'vontade'. Para ele, a vontade não seria outra coisa que não a razão prática, uma 


\section{GLOSA SOBRE NATUREZA E HISTÓRIA \\ CRISTIANE SOUZA BORZUK}

vez que só é possível que se derive as ações das leis mediadas pela razão. Desta forma, se a vontade é determinada pela razão, as ações de cada indivíduo, que são tidas como 'objetivamente necessárias', são também consideradas 'subjetivamente necessárias', ou seja: “(...) a vontade é a faculdade de escolher só aquilo que a razão, independentemente da inclinação, reconhece como praticamente necessário, quer dizer, como bom". XXXVI Entretanto, se se considera que a vontade não é, por ela mesma, totalmente de acordo com a razão, que, para Kant, é o que de fato acontece com os homens, então as ações que são consideradas necessárias do ponto de vista objetivo, do ponto de vista subjetivo são contingentes, o que implica em afirmar que a determinação da vontade segundo as leis objetivas torna-a uma obrigação.

Ao admitir esse distanciamento entre a vontade e a razão, Kant propõe a criação de mandamentos da razão, que seriam as representações de princípios objetivos que cumpririam a função de 'obrigante' para uma vontade. Os imperativos que, segundo Kant, representam a fórmula do mandamento, expressam “(...) a relação entre leis objetivas do querer em geral e a imperfeição subjetiva deste ou daquele ser racional, da vontade humana, por exemplo."XXXVII

Para Kant, os Imperativos só podem ser de duas ordens: os imperativos que ordenam hipoteticamente e os imperativos que ordenam categoricamente:

\footnotetext{
Os hipotéticos representam a necessidade prática de uma acção possível como meio de alcançar qualquer outra coisa que se quer (ou que é possível que se queira). $\mathrm{O}$ imperativo categórico seria aquele que nos representasse uma acção como objetivamente necessária por si mesma, sem relação com qualquer outra finalidade ${ }^{\mathrm{XXVIII}}$
}

Apesar de que todos os imperativos atuam de acordo com a representação de uma ação como boa, de acordo com o princípio de uma vontade boa (caso contrário não seria um imperativo, em termos kantianos), há uma diferença importante entre eles. Como o imperativo hipotético consiste em afirmar que "devo fazer alguma coisa porque quero qualquer outra coisa"XXXIX , ou seja, a ação é apenas um meio para atingir outro objetivo, ele não pode ser considerado como o princípio da moral. Este só pode ser o imperativo categórico: "Age apenas segundo uma máxima tal que possas ao mesmo tempo querer que ela se torne lei universal". ${ }^{\circ}$

Mas se Horkheimer e Adorno indicaram a impossibilidade desta tese, a impossibilidade, em nossa época, de derivar da razão, a moral, qual é o motivo de recorrermos a ela, e de tomarmos em tão alta conta este princípio? Talvez a consequência mais importante desta tese seja a convicção de que a condição fundamental para a livre escolha esteja no momento de liberdade.

Adorno encerra um dos aforismas de Mínima Moralia com a seguinte afirmação: "Não há nenhuma vida recta na falsa"XLI. Esta afirmação é prenhe de sentido. Nela está implícita a sua crítica às condições em que a vida humana está submetida sob o capitalismo administrado, e que encontra a sua marca mais evidente na falta de liberdade dos homens. Tal estado de coisas aparece no pensamento de Adorno não apenas como uma constatação, mas como a denúncia da impossibilidade de uma vida plena sob as condições às quais estamos submetidos, “(...) cuando los hombres reales son esclavos, tanto interna como exteriormente"XLII. Para ele, a liberdade de vontade é algo ainda a ser conquistado, e não já existente.

\section{Considerações finais}




\section{GLOSA SOBRE NATUREZA E HISTÓRIA \\ CRISTIANE SOUZA BORZUK}

Ao contrário do que prevê o dualismo entre as origens históricas ou naturais da constituição dos indivíduos e, decorrentes deles, a de seus comportamentos, este texto parte da noção de que há um imbricamento entre natureza e cultura. Buscar em apenas um dos polos da constituição das individualidades a resposta para a pergunta "Por que agem assim os homens", resulta em reducionismos que se distanciam das reais possibilidades de compreensão de tais fenômenos.

Ainda que, em nossa concepção, não seja possível ignorar os possíveis fatores naturais para a constituição da vida humana, em hipótese alguma encontramos nesses supostos motivos constitutivos a justificativa para o cometimento de crimes, a loucura, o suicídio etc. São relações dinâmicas e complexas que carecem do estabelecimento dos nexos históricos e socioeconômicos que determinam tais comportamentos.

Com a exclusão das circunstâncias em que se vive, ignora-se também que a origem dos comportamentos individuais se deve, em grande medida, a conflitos que são de natureza política e econômica, sendo, portanto, potencialmente superáveis. Neste caso, vê-se a impossibilidade de perceber a dimensão temporal da vida humana. As condições atuais de vida são mantidas quase como intactas, e os conflitos, que são datados, tornam-se naturais e, desta forma, imutáveis.

A tendência a separar, ou mesmo estabelecer a oposição entre a realidade social e os processos psíquicos, retirando estes últimos de seus nexos, converte-os em uma segunda natureza, que cabe a todos conhecer e, sobretudo, se contrapor.

\section{Notas}

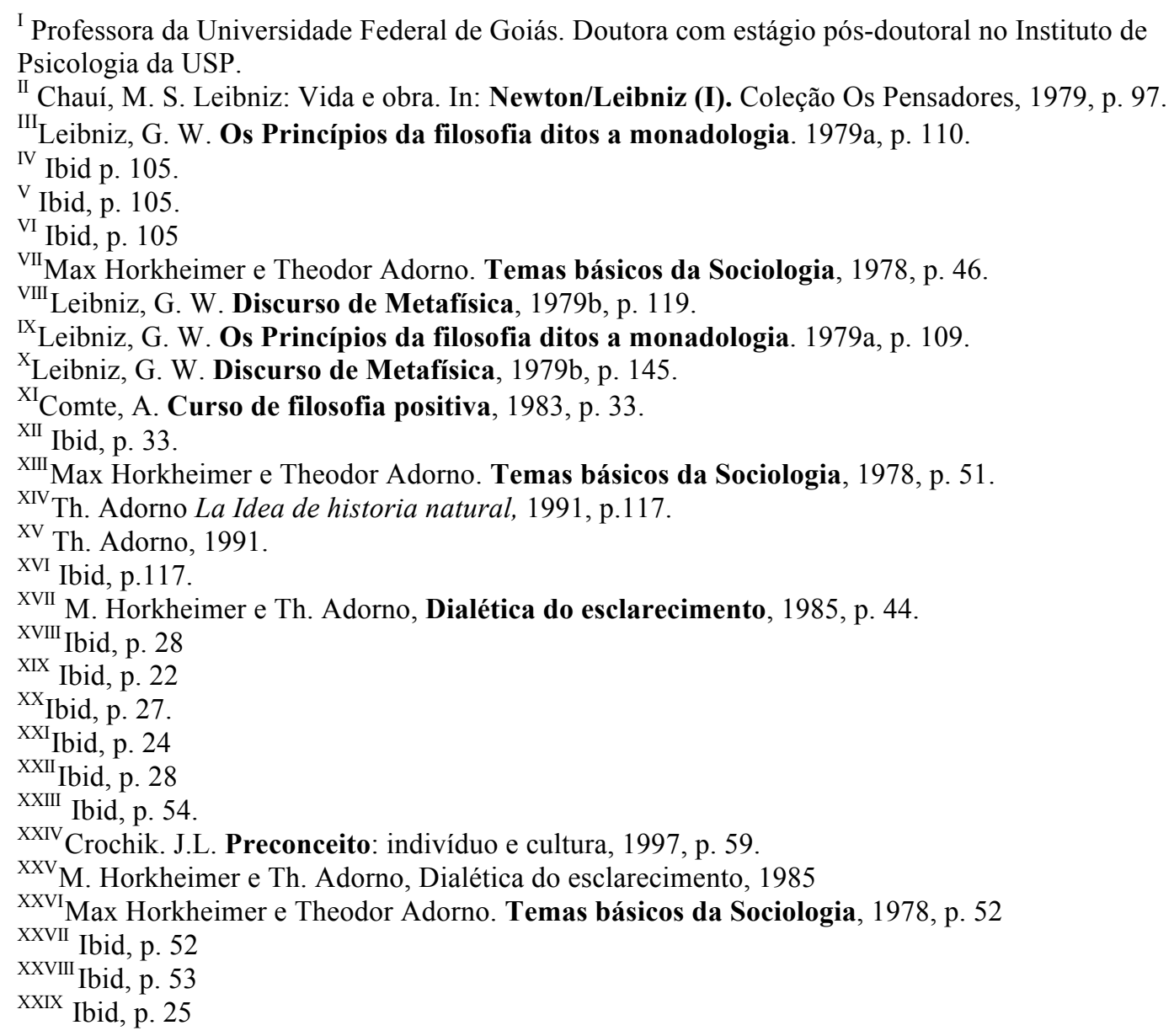


$\mathrm{XXX}$ Th. Adorno, Introdução à sociologia, 2008, p. 110.

XXXI Ibid, p. 119.

XXXII Th. Adorno, Introdução à sociologia, 2008, p. 123.

XXXIII (1978, p. 38). M. Horkheimer e Th. Adorno. Temas básicos da Sociologia, 1978, p. 38

XxxIV Ibid, p. 38.

${ }^{X X X V}$ Adorno, T.W. Educação após Auschwitz, 1995, p. 122.

XXXVI I. Kant. Fundamentação da metafísica dos costumes, 2005, p. 47.

XXXVII Ibid, p. 49.

XXXVIII Ibid, p. 50.

XXXIX Ibid, p. 86

${ }^{\mathrm{XL}}$ Ibid, p. 59. Grifos do autor.

${ }^{\mathrm{XLI}}$ Th. Adorno, Minima Moralia, 1951, p. 29.

XLII Th. Adorno, Los tabus sexuales y el derecho hoy, 1969, p. 109.

\section{Referências bibliográficas}

Adorno, T. W. Minima Moralia. Lisboa-Portugal: Edições 70, 1951.

Adorno, T. W. Los tabus sexuales y el derecho hoy. In Intervenciones: nueve modelos de critica. Caracas: Monte Avila Editores, 1969.

Adorno, T. W. La Idea de historia natural. In: Actualidad de la Filosofia. Barcelona: Paidós, 1991.

Adorno, T.W. Educação após Auschwitz. In: Educação e Emancipação. São Paulo: Paz e Terra, 1995.

Adorno, T. W. Introdução à sociologia. São Paulo: Editora UNESP, 2008.

Adorno, T. W., Frenkel-Brunswik, E., Levinson, D. J. \& Sanford, R. N. La personalidad autoritaria. Buenos Aires: Proyección, 1965.

Chauí, M. S. Leibniz: Vida e obra. In: Newton/Leibniz (I). Coleção Os Pensadores. São Paulo: Abril Cultural, 1979.

Comte, A. Curso de filosofia positiva. In: Comte. Coleção Os Pensadores.2ed., São Paulo: Abril Cultural, 1983.

Crochik, J. L. Preconceito: indivíduo e cultura. 2a ed. São Paulo: Robe Editorial, 1997.

Horkheimer, M.; Adorno, T. W. Temas básicos da sociologia. São Paulo: Editora Cultrix, 1978.

Horkheimer, M.; Adorno, T. W. Dialética do esclarecimento: fragmentos filosóficos. Rio de Janeiro: Jorge Zahar Editor, 1985.

Kant, I. Fundamentação da metafísica dos costumes. Lisboa: Edições 70, 2005.

Leibniz, G. W. Os Princípios da filosofia ditos a monadologia. In: Newton, Leibniz (I). Coleção Os Pensadores. São Paulo: Abril Cultural, 1979a.

Leibniz, G. W. Discurso de metafísica. In: Newton, Leibniz (I). Coleção Os Pensadores. São Paulo: Abril Cultural, 1979b. 